\section{Case Reports in Neurology}

Case Rep Neurol 2021;13:131-134

DOI: $10.1159 / 000512811$

Published online: February 16, 2021 (c) 2021 The Author(s)

Published by S. Karger AG, Basel OPEN

www.karger.com/crn

This article is licensed under the Creative Commons Attribution-NonCommercial 4.0 International License (CC BY-NC) (http://www.karger.com/Services/OpenAccessLicense).

Usage and distribution for commercial purposes requires written permission.

\title{
A Case of Alpha-Pyrrolidinopentiophenone (Flakka)-Induced Ischemic Stroke
}

\author{
Tommi Heinonen $^{a, c} \quad$ Antti Korvenoja ${ }^{b} \quad$ Eero Pekkonen ${ }^{a, c}$ \\ aDepartment of Neurology, Helsinki University Hospital, Helsinki, Finland; ${ }^{\text {b} R a d i o l o g y, ~}$ \\ HUS Diagnostic Center, University of Helsinki and Helsinki University Hospital, \\ Helsinki, Finland; 'Department of Clinical Neurosciences (Neurology), University of \\ Helsinki, Helsinki, Finland
}

\section{Keywords}

Recreational drug · Flakka · Stroke

\begin{abstract}
Alpha-pyrrolidinovalerophenone ( $\alpha$-PVP) is a designer drug, the mechanism of action of which resembles that of cocaine and amphetamine. New data about the side effects of $\alpha$-PVP are emerging. We present a case report of an acute ischemic stroke following the recreational use of $\alpha$-PVP. The ischemic lesions were located in the middle cerebral artery and deep watershed areas of the left cerebral hemisphere. Occupational therapy and physiotherapy were initiated, and the patient was discharged with only a mild right hemiparesis.
\end{abstract}

(c) 2021 The Author(s)

Published by S. Karger AG, Basel

\section{Introduction}

Alpha-pyrrolidinovalerophenone ( $\alpha$-PVP), or "flakka" by its street name, is a synthetic stimulant used recreationally. $\alpha$-PVP is related to other cathinone derivates often commonly referred to as "bath salts," and the mechanism of action resembles that of cocaine and amphetamine by inhibiting dopamine and norepinephrine reuptake [1]. Unlike older drugs, the adverse effects of newer designer drugs are not as well known. The previously reported serious adverse effects of $\alpha$-PVP included psychosis and catatonia [2], myocardial infarction [3], and 


\section{Case Reports in Neurology}

Case Rep Neurol 2021;13:131-134

DOI: 10.1159/000512811

(c) 2021 The Author(s). Published by S. Karger AG, Basel www.karger.com/crn

Heinonen et al.: Flakka-Induced Stroke

Stevens-Johnson syndrome [4], but not stroke. $\alpha$-PVP is banned in multiple EU countries including Finland. Here we present a case report of an acute ischemic stroke following injection of $\alpha$-PVP.

\section{Case Report}

A Finnish male patient in his sixties with hepatitis $\mathrm{C}$ and osteoarthrosis of both knees was admitted to the emergency department because of acute right-sided hemiparesis that had started a day before the admission. Prior to the onset of hemiparesis, the patient's friend had injected a dose of $\alpha$-PVP into the patient's neck. The intended injection site was the left external jugular vein, since the peripheral veins were damaged due to numerous injections. Before the injection, the drug had been mixed with tap water and injected using a clean needle and a microfilter provided by a nonprofit organization aimed at diminishing health complications from drug use.

The clinical neurological evaluation at the emergency department showed right-sided hemiparesis, no visual deficits, and no aphasia or dysarthria. A head CT demonstrated infarctions along the left sulcus centralis. Only a small puncture wound without surrounding hematoma was found on the patient's neck.

CT angiography of the head and neck arteries showed no dissection or other signs of trauma of the carotid or vertebral arteries, and no critical stenosis. Only minor atherosclerotic plaques were found. In the distal part of the basilar artery, either vasospasm or stenosis due to atherosclerosis was suspected. Thrombosis of the left jugular vein was also suspected.

Aspirin $250 \mathrm{mg}$ p.o. and enoxaparin $40 \mathrm{mg}$ s.c. as a prophylactic dose against deep vein thrombosis were administered, and the patient was admitted to the neurology ward. Further investigations included a neck ultrasound, which ruled out thrombosis of the jugular vein. Head MRI showed multiple new ischemic lesions in the left cerebral hemisphere (Fig. 1). The lesions were mainly located in the deep watershed area of the centrum semiovale. MRA of the carotid and cerebral arteries did not show vasospasm or clinically relevant atherosclerotic stenosis. There was no indication of puncture of the left internal carotid artery in these studies.

Atrial fibrillation was not found on 48-h ECG monitoring. Transthoracic and transesophageal echocardiography showed no evidence of endocarditis or intracardial thrombi. Clinically irrelevant, small patent foramen ovale was found. A urine drug screen was positive for benzodiazepines, and the patient reported occasional use of benzodiazepines. A full thrombophilia workup was negative and along with a normal complete blood count ruled out most common thrombophilias and hematological disorders. LDL cholesterol was $2.2 \mathrm{mmol} / \mathrm{L}$, and $\mathrm{HbA}_{1 \mathrm{c}}$ was normal.

The patient was evaluated, and rehabilitation was initiated by an occupational therapist. However, the patient left the hospital on the fifth day of his own will before a complete physiotherapy evaluation. At discharge, the patient had a mild right-sided hemiparesis but could walk with the aid of forearm crutches he had already been using because of osteoarthrosis. Prescriptions of aspirin $100 \mathrm{mg}$ and atorvastatin $10 \mathrm{mg}$ once per day were given, and the patient was advised to continue occupational therapy at the local healthcare center to rehabilitate right arm functions.

\section{Karger'"}




\section{Case Reports in Neurology}

\section{Discussion}

We strongly suspect that the patient's stroke was caused by the use of $\alpha$-PVP, although the exact mechanism remains unknown. The patient used a clean needle with a microfilter, which lowers the risk of embolic adulterants to be the direct cause of the ischemic stroke. The comprehensive evaluation ruled out other major causes of stroke, and the onset of the stroke was immediately after the $\alpha$-PVP injection. The urine drug screen was only positive for benzodiazepines, which rules out other confounding substances.

We did not find previous reports of ischemic strokes caused by $\alpha$-PVP, although cardiovascular events such as myocardial infarction had been previously reported [3]. Structurally and pharmacologically synthetic cathinones are similar to amphetamine, and physiological changes include hypertension, arrythmia, and vasoconstriction, which are known to cause strokes [5].

The normal urine drug screen used at the emergency departments in Finland does not demonstrate the use of synthetic drugs. As this case demonstrates, patients seeking medical aid sometimes willingly share information about illicit drug use, if only they are asked.

\section{Statement of Ethics}

This research was conducted ethically in accordance with the World Medical Association Declaration of Helsinki. The subject in this paper gave written informed consent for publication of the case including publication of images.

\section{Conflict of Interest Statement}

The authors have no conflicts of interest to declare.

\section{Funding Sources}

The authors received no funding for the publication of the manuscript.

\section{Author Contributions}

T. Heinonen: drafting, data acquisition, and writing. A. Korvenoja: data acquisition, visualization, and revision of the manuscript. E. Pekkonen: drafting, supervision, and revision of the manuscript.

\section{References}

1 Glennon RA, Young R. Neurobiology of 3,4-methylenedioxypyrovalerone (MDPV) and $\alpha$-pyrrolidinovalerophenone ( $\alpha$-PVP). Brain Res Bull. 2016 Sep;126(Pt 1):111-26.

2 Richman EE, Skoller NJ, Fokum B, Burke BA, Hickerson CA, Cotes RO. $\alpha$-Pyrrolidinopentiophenone ("flakka") catalyzing catatonia: a case report and literature review. J Addict Med. 2018 Jul/Aug;12(4):336-8.

\section{Karger'=}




\section{Case Reports in Neurology}

\begin{tabular}{l|l}
\hline Case Rep Neurol 2021;13:131-134 \\
\hline DOI: 10.1159/000512811 & $\begin{array}{l}\text { @ 2021 The Author(s). Published by S. Karger AG, Basel } \\
\text { www.karger.com/crn }\end{array}$ \\
\hline
\end{tabular}

Heinonen et al.: Flakka-Induced Stroke

3 Cherry SV, Rodriguez YF. Synthetic Stimulant Reaching Epidemic Proportions: Flakka-Induced ST-Elevation Myocardial Infarction with Intracardiac Thrombi. J Cardiothorac Vasc Anesth. 2017 Feb;31(1):e13-4.

4 İlhan B, Doğan H, Şahin EA, Karslıoğlu N, Koçak Ö. Novel complication of Flakka: Stevens-Johnson syndrome/Toxic epidermal necrolysis overlap. Am J Emerg Med. 2019 Mar;37(3):562.e1-3.

5 Prosser JM, Nelson LS. The toxicology of bath salts: a review of synthetic cathinones. J Med Toxicol. 2012 Mar;8(1):33-42.

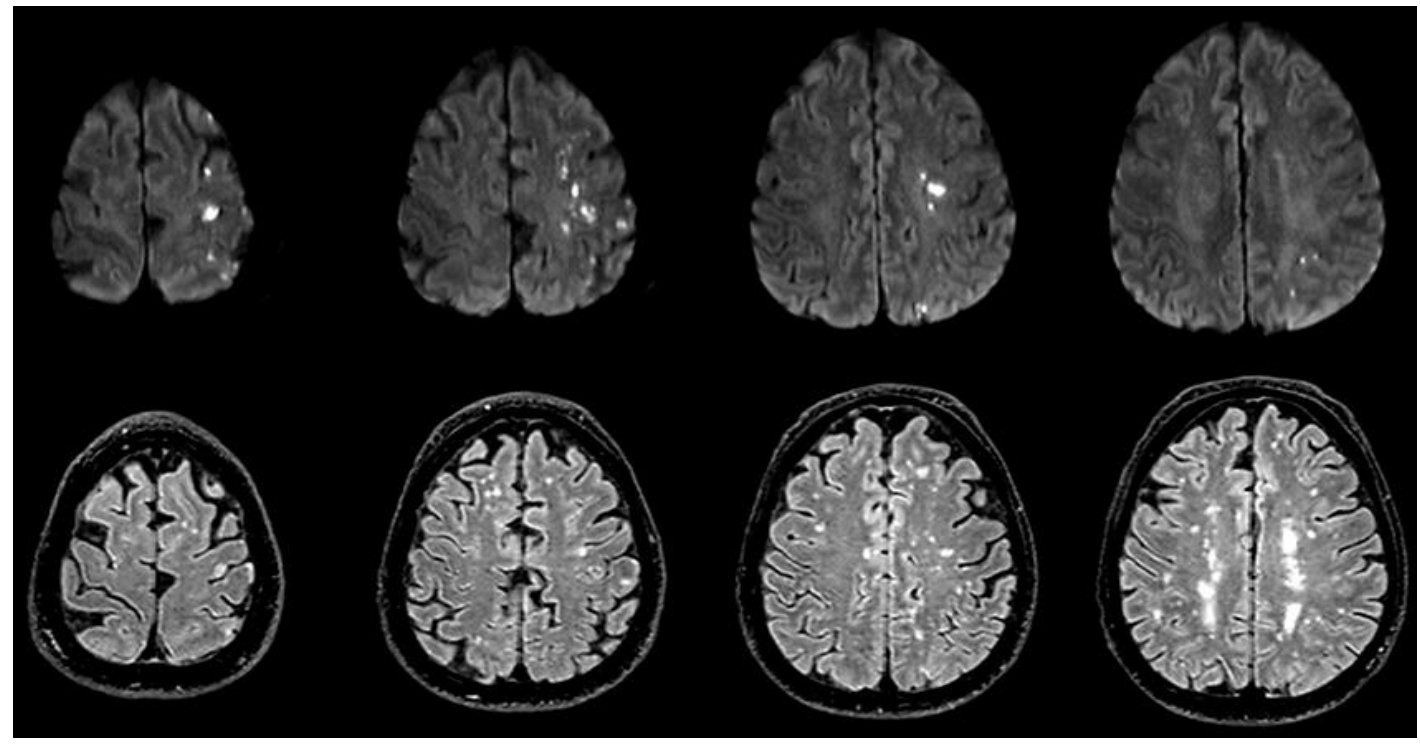

Fig. 1. Top row: representative 3-mm DWI trace image slices showing scattered restricted diffusion areas in the middle cerebral artery and deep watershed areas. Bottom row: FLAIR image slices (1 mm slice thickness) at corresponding levels. The lesions on DWI have a high signal intensity on the FLAIR images, consistent with acute infarction. Further, there are confluent, deep white matter hyperintensities with no diffusion restriction and a distribution consistent with chronic vascular lesions. 